\title{
Future directions in cardiovascular disease risk prediction
}

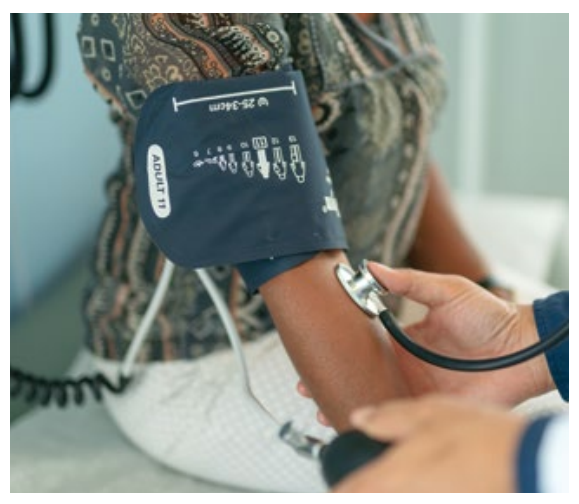

CPD

Jenny A Doust, Carissa Bonner, Katy JL Bell

DIAGNOSING AND MANAGING risk factors for cardiovascular disease (CVD) is so routine in general practice that it is possible to underestimate its importance in reducing cardiovascular events. If cardiovascular deaths had remained at the levels seen at their peak in 1968 in Australia, there would have been approximately 200,000 additional deaths in 2015, a year in which there were 159,052 total deaths. ${ }^{1}$ Much of the decline has been due to decreases in smoking, blood pressure and cholesterol levels even prior to medical interventions, but widespread use of blood pressurelowering and lipid-lowering therapy has also played a significant part. ${ }^{2}$

Deaths and disability from CVD could be reduced even further by improved targeting of therapies. It is recommended that patients who are at high risk of CVD take both blood pressure-lowering and lipid-lowering medications. ${ }^{3}$ The current Australian guidelines produced by the National Vascular Disease Prevention Alliance (NVDPA) define high risk as a risk of $>15 \%$ of a CVD event over the next five years. In 2017, the Pharmaceutical Benefits Advisory Committee removed restrictions on prescribing of statins to allow prescribing in accordance with the guidelines. Currently, only $25 \%$ of people aged 45-74 years who are at high risk are taking both types of medications, as are only $35 \%$ of those aged $>75$ years. ${ }^{4}$ It is unknown how many of those not taking both types of medications had not been assessed and offered medication, and how many had been offered medication but did not want to take it or had stopped because of side effects. However, based on MedicineInsight data, only $17 \%$ of adults aged $\geq 45$ years have all the risk factors recorded to calculate cardiovascular risk. ${ }^{5}$ A new Medicare Benefits Schedule (MBS) item became available in 2019 to further support the use of absolute risk assessment in general practice.

Being able to assess whether a patient is at high risk for CVD requires the use of a CVD risk calculator. Individual risk factors, such as blood pressure and lipid levels, are poor predictors of overall (or absolute) cardiovascular risk, and clinicians are not able to intuitively combine these factors accurately. ${ }^{6}$ Rod Jackson and his team in New Zealand developed one of the first ways to calculate cardiovascular risk, using coloured charts. ${ }^{7}$ In Australia, the NVDPA has developed a website that allows clinicians to calculate cardiovascular risk online (www.cvdcheck.org.au). The risk calculator is now also embedded in the software programs used by the majority of general practitioners (GPs) in Australia.

The risk calculator currently recommended by the NVDPA is based on 
the Framingham Risk Equation. ${ }^{8}$ More than 360 other CVD risk equations have been developed, ${ }^{9}$ many incorporating risk factors not included in the Framingham Risk Equation. The objective of this review is to provide an update for Australian GPs on recent developments in cardiovascular risk calculators and their application, and suggest potential future directions.

\section{The purpose of cardiovascular disease risk prediction}

CVD risk calculators are used to determine an individual's risk of developing CVD in the short term, generally five or 10 years, to determine if the patient is at high risk. Prescription of preventive medication, generally both lipid-lowering and blood pressure-lowering medication, is recommended for individuals at high risk, for whom it is most likely that benefits will outweigh the harms. ${ }^{2}$ CVD risk calculators should not be used to determine whether counselling and advice for lifestyle factors should be given to individuals, as this is recommended regardless of the CVD risk estimate. Patients who smoke or are obese or not physically active should be encouraged to adopt healthier lifestyles. Patients with very high blood pressure or lipid levels should also be prescribed medication to lower these, and patients with other conditions that are considered high risk for CVD should be treated with both medications, irrespective of estimated CVD risk (Table 1$){ }^{2}$

\section{The accuracy of cardiovascular disease risk prediction}

The Framingham Risk Equation used in the NVDPA calculator is based on the Framingham Heart Study and the Framingham Offspring Study cohorts, who had baseline measures taken between 1968 and $1975 .{ }^{8}$ In addition to the age of the study and the limited number of potential risk factors evaluated, major limitations include the restricted geographic and socioeconomic diversity of the participants, and that $100 \%$ of participants were of European American ancestry. Despite this, the Framingham Risk Equation shows good discrimination even in a recent Australian population (Table 1), ${ }^{10}$ and the traditional risk factors explain much of the risk variance in the population.

Many new factors have been shown to increase the relative risk of CVD. Showing increased relative risk, however, is not sufficient to show that a risk factor is useful for inclusion in CVD risk prediction. Since risk factors tend to cluster, they do not always add predictive value. For example, body mass index (BMI) does not add predictive value to models that include blood pressure and cholesterol. ${ }^{11}$

Ideally, new tests and factors would be evaluated in randomised controlled trials. However, given the size and duration of trials required to do this, an approach that evaluates how the risk factor improves CVD risk prediction is often required. The addition of a risk factor is deemed to better identify who to treat if it improves: 1) discrimination, 2) classification and 3) calibration, and if the overall expected benefits of testing and treatment outweigh the harms. ${ }^{12}$ Discrimination is most often evaluated using the $\mathrm{C}$ statistic (or the closely related area under the receiver operating curve). A test that perfectly discriminates between those who have a disease and those who do not has a $\mathrm{C}$ statistic of 1 . The net reclassification index is the sum of the proportions of people who are correctly and incorrectly reclassified as low and high risk because of the addition of the risk factor, and it has a maximum value of 2. Calibration measures whether predictions systematically overestimate or underestimate the actual probability of an event. A substantial proportion of contemporary populations are treated with blood pressure-lowering or lipid-lowering medications, causing older risk calculators such as the Framingham Risk Equation to overestimate the observed risk of events. Evaluations of the calibration of a risk calculator need to take treatment frequency in the population into account, as their purpose is to predict cardiovascular events (and therefore potential benefits of treatment) for an untreated patient.

Three important risk calculators have been developed recently in the USA
(Pooled Cohort Equation - atherosclerotic CVD [PCE-ASCVD]), ${ }^{11}$ the UK (QRISK, recently updated to QRISK3) ${ }^{13}$ and New Zealand (PREDICT- 1$).{ }^{14}$ The main features of these risk equations and the Framingham Risk Equation currently recommended by the NVDPA, including estimates of their accuracy and calibration, are shown in Table 1. Note that the estimated accuracy of the QRISK3 and PREDICT-1 equations may be overstated, as they are tested using the same population cohort as was used for development. Notably, the three new equations include a number of new risk factors, particularly ethnicity and measures of socioeconomic deprivation.

Other risk factors were considered when developing these newer models but were not included in the final models. As an example, the PCE-ASCVD model does not include family history, BMI or waist circumference as these factors did not improve discrimination beyond the traditional risk factors in a French risk model or in the development of the PCE-ASCVD equation. ${ }^{15}$

\section{Individualising risk prediction}

The current NVDPA guidelines recommend that the traditional risk factors be used for assessment, but additional risk factors can be used to guide decision making for an individual. For example, medication can be recommended to patients from high-risk ethnic groups who are assessed as being at moderate risk by the calculator.

CVD risk calculators estimate risk on the basis of population estimates. Substantial numbers of people need to be treated to prevent a cardiovascular event, many of whom would never have had an event even without treatment, while a significant proportion of people classified as low risk will subsequently have a cardiovascular event (Table 2). It would be ideal to use tests that can more accurately assess the cardiovascular risk for an individual patient.

The United States Preventive Services Task Force has recently reviewed the evidence for some tests that are potential candidates for this: ankle-brachial index, 
Table 1. Description of commonly used cardiovascular risk predictors

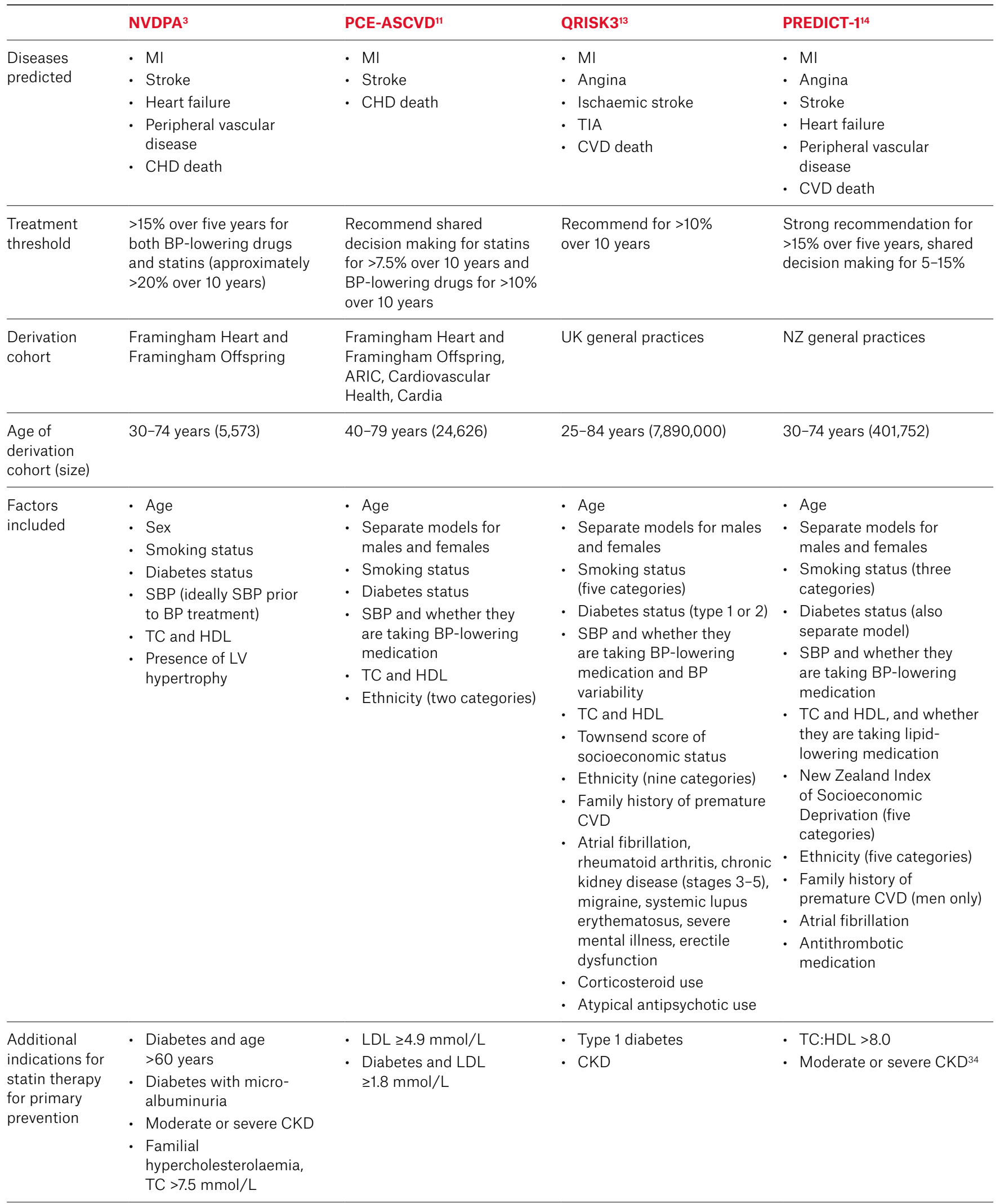


Table 1. Description of commonly used cardiovascular risk predictors (cont'd)

\begin{tabular}{|c|c|c|c|c|}
\hline & NVDPA $^{3}$ & PCE-ASCVD ${ }^{11}$ & QRISK3 $^{13}$ & PREDICT-1 ${ }^{14}$ \\
\hline $\begin{array}{l}\text { Additional } \\
\text { indications for } \\
\text { blood pressure } \\
\text { lowering } \\
\text { therapy for } \\
\text { primary } \\
\text { prevention }\end{array}$ & $\begin{array}{l}\text { - Diabetes and age } \\
>60 \text { years } \\
\text { - Diabetes with micro- } \\
\text { albuminuria } \\
\text { - Moderate or severe CKD } \\
\text { - } \mathrm{BP} \geq 140 / 90 \mathrm{mmHg} \text { if } \\
\text { moderate absolute risk, } \\
\mathrm{BP} \geq 160 / 100 \mathrm{mmHg} \text { if } \\
\text { low risk }{ }^{35}\end{array}$ & $\begin{array}{l}\text { - } \mathrm{BP}>140 / 90 \mathrm{mmHg} \\
\text { - Diabetes or renal disease } \\
\text { and } \mathrm{BP}>130 / 80 \mathrm{mmHg}^{36}\end{array}$ & $\begin{array}{l}\text { - } \mathrm{ABPM} \text { or HBPM } \\
>150 / 95 \mathrm{mmHg} \\
\text { - } \text { Diabetes or renal disease } \\
\text { and ABPM or HBPM } \\
>135 / 85 \mathrm{mmHg} \\
\text { - } \mathrm{ABPM} \text { or } \mathrm{HBPM} \\
>135 / 85 \mathrm{mmHg} \text { and age } \\
<60 \text { years to consider } \\
\text { medication }{ }^{37}\end{array}$ & - $\mathrm{BP}>160 / 100 \mathrm{mmHg}^{34}$ \\
\hline $\begin{array}{l}\text { C statistic - } \\
\text { women }\end{array}$ & $0.80(0.76,0.84)\left(\right.$ Australia) ${ }^{10}$ & $\begin{array}{l}0.84(0.80,0.87)(\text { Australia })^{10} \\
0.74(0.71,0.76)(\text { USA })^{38} \\
0.71(0.70,0.72)(N Z)^{14}\end{array}$ & $0.88(0.88,0.88)(U K)^{13}$ & $0.73(0.72,0.73)(\mathrm{NZ})^{14}$ \\
\hline Calibration & $\begin{array}{l}\text { Overestimated risk for } \\
\text { Australian population }{ }^{10}\end{array}$ & $\begin{array}{l}\text { Overestimated risk for } \\
\text { Australian }{ }^{10} \text { and NZ } \\
\text { populations }{ }^{14}\end{array}$ & $\begin{array}{l}\text { Well calibrated for UK } \\
\text { population }^{13}\end{array}$ & $\begin{array}{l}\text { Well calibrated for NZ } \\
\text { population }^{14}\end{array}$ \\
\hline $\begin{array}{l}\text { ABPM, ambulator } \\
\text { kidney disease; } \mathrm{Cl} \\
\text { ventricular; } \mathrm{MI}, \mathrm{my} \\
\text { atherosclerotic cal }\end{array}$ & $\begin{array}{l}\text { blood pressure monitoring; ARIC, } \\
\text { D, cardiovascular disease; HBPM, } \\
\text { ocardial infarction; NVDPA, Nation } \\
\text { diovascular disease; SBP, systolic b }\end{array}$ & $\begin{array}{l}\text { Australian Research Integrity Comm } \\
\text { ome blood pressure monitoring; HD } \\
\text { I Vascular Disease Prevention Alliar } \\
\text { lood pressure; TC, total cholesterol; }\end{array}$ & $\begin{array}{l}\text { ee; } B P, \text { blood pressure; } C H D \text {, cor } \\
\text { high-density lipoprotein; } L D L, \text { lo } \\
\text {; NZ, New Zealand; PCE-ASCVL } \\
\text { A, transient ischaemic attack }\end{array}$ & $\begin{array}{l}\text { ry heart disease; } C K D \text {, chronic } \\
\text { lensity lipoprotein; } L V \text {, left } \\
\text { oled Cohort equation - }\end{array}$ \\
\hline
\end{tabular}

coronary artery calcium scoring, high-sensitivity C-reactive protein ${ }^{16}$ and exercise electrocardiography (ECG). ${ }^{17}$ A summary of their findings is shown in Table 3. Coronary artery calcium scoring has also been assessed in a relatively small randomised controlled trial, randomising individuals to scanning or not prior to assessment of traditional risk factors. The trial of 2137 patients followed for four years found no evidence of a difference in clinical outcomes (ie myocardial infarction, cardiac death, all-cause mortality). ${ }^{18}$ A greater number of patients who had undergone scanning commenced blood pressure medication (presumably because of increased classification of patients as being high risk), with a subsequent improvement in blood pressure levels; however, there was no change in medication adherence for those taking medication. Two small randomised controlled trials have assessed exercise ECG in patients at high risk and found no evidence of a difference in health outcomes, although the trials were also limited by their small sizes. ${ }^{17}$ To date, there is no convincing evidence for the use of these non-traditional tests in routine risk assessment.

Another potential avenue is the use of genetic testing, such as polygenic risk scores. The UK Biobank project contains genetic information for more than half a million individuals and has identified 1.7 million genetic variants contributing to the risk of coronary artery disease. However, improvement in risk prediction beyond that of the traditional risk factors was very modest, improving the $C$ statistic from 0.670 to $0.696 .^{19}$

\section{Aboriginal and Torres Strait Islander population}

While the Framingham Risk Equation overestimates CVD risk in the general Australian population, it underestimates risk in the Aboriginal and Torres Strait Islander population by approximately one-third. ${ }^{20}$ Until a specific model for this population is developed or better calibrated, it is important that clinicians are aware of this underestimation and upwardly adjust estimates of CVD risk if they are using a CVD risk calculator for this population. It is also recommended that assessment begins earlier (eg at the age of 18 years), ${ }^{21}$ with particular consideration given to other conditions not covered by the Framingham Risk Equation that have been shown to place an individual at high risk of CVD.

\section{Use in the elderly}

The decision of whether to prescribe (or to continue to prescribe) lipid-lowering and blood pressure-lowering medication for the elderly is complex. The risk of a CVD event greatly increases with age, increasing the potential benefits of treatment; however, the risk of harmful side effects also increases, as do comorbidities and competing causes 
of mortality. A recent study using an intervention to improve the alignment between the health priorities of elderly patients who have multimorbidities with their clinical care led to three times as many patients stopping cardiovascular medication than usual care. ${ }^{22}$

\section{Communication}

Since CVD prevention involves prescribing medication to healthy, asymptomatic individuals, a shared decision-making approach is essential. ${ }^{23}$ Reviews have concluded that communicating baseline absolute risk and how treatment can modify this risk is the best way to help patients understand their own risk and consider action to reduce this, including lifestyle change or medication. ${ }^{24}$ This is particularly important for individuals at lower levels of risk, where the potential benefit of treatment is smaller. Many individuals require evidence of a substantial reduction in risk before they consider it worthwhile to take daily

Table 2. Classification of patients using Framingham and PCE-ASCVD risk calculators*

\begin{tabular}{|c|c|c|}
\hline & NVDPA & PCE-ASCVD 2013 \\
\hline $\begin{array}{l}\text { Proportion of women aged } 40-74 \text { years without } \\
\text { CVD classified as high risk by risk equation }\end{array}$ & $2 \%(\text { Australia })^{10}$ & $\begin{array}{l}18 \% \text { (Australia) }^{10} \\
20 \%(\text { USA) }\end{array}$ \\
\hline $\begin{array}{l}\text { Proportion of men aged } 40-74 \text { years without } \\
\text { CVD classified as high risk by risk equation }\end{array}$ & 17\% (Australia) ${ }^{10}$ & $\begin{array}{l}46 \%(\text { Australia })^{10} \\
26 \%(\text { USA) })^{38}\end{array}$ \\
\hline $\begin{array}{l}\text { Proportion of women aged } 40-74 \text { classified as } \\
\text { low risk who have a CVD event within } 12 \text { years }\end{array}$ & $3 \%$ (Australia) $^{10}$ & $1 \%$ (Australia) $^{10}$ \\
\hline $\begin{array}{l}\text { Proportion of men aged } 40-74 \text { classified as } \\
\text { low risk who have a CVD event within } 12 \text { years }\end{array}$ & $7 \%$ (Australia) $^{10}$ & $3 \%$ (Australia) $^{10}$ \\
\hline \multicolumn{3}{|c|}{$\begin{array}{l}\text { *These estimates are based on the risk calculator alone and do not include the proportion who are } \\
\text { classified as high risk by other clinical factors, such as the presence of chronic kidney disease. } \\
\text { CVD, cardiovascular disease; NVDPA, National Vascular Disease Prevention Alliance; PCE-ASCVD, } \\
\text { Pooled Cohort Equation - atherosclerotic cardiovascular disease }\end{array}$} \\
\hline
\end{tabular}

medication. ${ }^{25}$ However, Australian GPs have identified communication as one of the barriers to conducting risk assessments in general practice, particularly for patients with perceived low health literacy. ${ }^{26}$ Reviews of decision support tools for CVD risk communication have noted that a wide range of resources are available online. ${ }^{27}$ Unfortunately, few met criteria to meet the needs of most people, particularly those with low health literacy. ${ }^{28}$

GPs can address this by explaining CVD risk using simple frequencies to explain both the risk and benefit of medication. ${ }^{29}$ For example, a patient with $10 \%$ risk could be told: 'Out of 100 people like you, approximately 10 will have a heart attack or stroke in the next five years. If all 100 take a statin, approximately two heart attacks or strokes could be prevented. Approximately one person will have muscle aches and pains, but if this happens we can stop the medication.' Recent calculators have generally used a 10-year time frame, and this may be more effective for conveying risk and motivating lifestyle changes. ${ }^{30}$

There is increasing interest in 'heart age' calculators, which have been promoted around the world including in Australia, New Zealand and the UK. ${ }^{31}$ While there are claims that giving patients an 'older' heart age can motivate them

Table 3. Review of non-traditional risk factors for cardiovascular disease risk assessment by United States Preventive Services Task Force

\begin{tabular}{|c|c|c|c|}
\hline & Discrimination & Reclassification & Harms \\
\hline $\begin{array}{l}\text { Coronary artery } \\
\text { calcium }^{16}\end{array}$ & $\begin{array}{l}\text { Improved discrimination of } \\
\text { PCE-ASCVD from } 0.74 \text { to } \\
0.76 \text { in Multi-Ethnic Study } \\
\text { of Atherosclerosis (MESA) } \\
\text { cohort (USA) }\end{array}$ & $\begin{array}{l}\text { NRI of } 0.12 \text { when added to PCE-ASCVD } \\
\text { (mostly due to correctly reclassifying patients } \\
\text { with events from low to high risk; somewhat } \\
\text { offset by incorrect reclassification of patients } \\
\text { without events from low to high risk) }\end{array}$ & $\begin{array}{l}\text { Radiation exposure }<2 \text { mSv } \\
\text { (chest } X \text {-ray } 0.1 \mathrm{mSv} \text { ), possible } \\
\text { increase in flow-on testing, } \\
\text { particularly cardiac imaging }\end{array}$ \\
\hline $\begin{array}{l}\text { High-sensitivity } \\
\text { C-reactive protein }{ }^{16}\end{array}$ & $\begin{array}{l}\text { No change when added to } \\
\text { PCE-ASCVD }\end{array}$ & $\begin{array}{l}\text { NRI not statistically significant when added } \\
\text { to PCE-ASCVD }\end{array}$ & Very limited data \\
\hline $\begin{array}{l}\text { Resting or exercise } \\
E_{C G}{ }^{17}\end{array}$ & $\begin{array}{l}\text { Five studies, improved } \\
\text { C statistic by } 0.02-0.03 \text { when } \\
\text { added to Framingham Risk } \\
\text { Equation or PCE-ASCVD }\end{array}$ & $\begin{array}{l}\text { Improvement in reclassification varying } \\
\text { between } 0.036 \text { and } 0.030 \text {, but using previous } \\
\text { threshold levels for treatment decisions }\end{array}$ & Very limited data \\
\hline
\end{tabular}

ECG, electrocardiography; NRI, net reclassification index; PCE-ASCVD, Pooled Cohort Equation - atherosclerotic cardiovascular disease 
to change their lifestyles, a review of biological age formats found no evidence that this is more effective than absolute risk formats. ${ }^{32}$ Anecdotally, New Zealand GPs find this to be a useful communication tool to get people interested in their CVD risk and lifestyle change, but absolute risk must be used when considering medication. ${ }^{33}$ This is important not only to determine who is at high risk and likely to benefit from medication, but also to enable a shared, informed decision with the patient.

\section{Conclusion}

More recent CVD risk calculators improve CVD risk prediction, particularly those with included measures of ethnicity and socioeconomic deprivation. Much research is being conducted into potential new measures for CVD risk prediction, such as machine learning techniques, genetics and more sophisticated imaging. However, to date these techniques have not shown a greater ability to predict CVD than risk calculators built using more traditional clinical factors.

The current threshold for recommended treatments in Australia means that a substantial proportion of individuals who subsequently develop CVD are currently classified as low risk (Table 2). Lowering the recommended threshold would improve access to preventive treatment and lower the incidence of CVD, but would also result in a large proportion of the population being recommended treatment with both blood pressurelowering and lipid-lowering medication. Some individuals would be happy to take daily medication to reduce this risk, but others would not. It is important that any decision is in line with the patient's values regarding their healthcare and that the decision is reviewed as the patient's circumstances change.

Many patients at high risk of CVD, even using the current threshold, are not being assessed for their risk of CVD and therefore are missing out on potential treatment. It is important that GPs use the new MBS heart health check item numbers or other systematic approaches to ensure that their patients are being assessed and reviewed, and offered treatment where appropriate.

\section{Authors}

Jenny A Doust BMBS, PhD, FRACGP, Clinical Professorial Research Fellow, Centre for Longitudinal and Life Course Research, School of Public Health, University of Queensland, Qld. j.doust@uq.edu.au

Carissa Bonner MPH, PhD, Research Fellow, Sydney School of Public Health, Sydney Medical School, Faculty of Medicine and Health, The University of Sydney, NSW

Katy JL Bell MBChB, MMed, PhD, NHMRC Emerging Leader Research Fellow, Sydney School of Public Health, Sydney Medical School, Faculty of Medicine and Health, The University of Sydney, NSW

Competing interests: JAD is on the Clinical Committee of the National Heart Foundation of Australia. KJLB reports an Early Career Research Transition Grant from the Foundation for High Blood Pressure Research, outside the submitted work. CB reports peer-reviewed research grants and one fellowship from the National Heart Foundation of Australia, in addition to reimbursement for time to prepare/participate in a GP webinar on CVD guidelines, and in-kind support for projects. CB was also asked for advice on the National Heart Foundation of Australia consumer heart age calculator and peer-reviewed grants in 2019. CB reports grants and non-financial support from The

Royal Australian College of General Practitioners (RACGP), as well as grants from the National Health and Medical Research Council (NHMRC) and Diabetes Australia, outside the submitted work. In addition, CB and JAD have developed an Australian CVD guidelines website at www.auscvdrisk.com.au for GPs, with review of intellectual property pending.

Funding: JAD reports grants from the NHMRC, National Heart Foundation of Australia and the RACGP, during the conduct of the study. KJLB reports an Investigator Grant from the NHMRC during the conduct of the study.

Provenance and peer review: Commissioned, externally peer reviewed.

\section{References}

1. Australian Institute of Health and Welfare. Trends in cardiovascular deaths. Bulletin 141. Cat. No. AUS 216. Canberra, ACT: AlHW, 2017.

2. Ford ES, Capewell S. Proportion of the decline in cardiovascular mortality disease due to prevention versus treatment: Public health versus clinical care. Annu Rev Public Health 2011;32:5-22. doi: 10.1146/annurev-publhealth-031210-101211.

3. National Vascular Disease Prevention Alliance. Guidelines for the management of absolute cardiovascular disease risk. Melbourne, Vic: National Stroke Foundation, 2012.

4. Banks E, Crouch SR, Korda RJ, et al. Absolute risk of cardiovascular disease events, and blood pressure - And lipid-lowering therapy in Australia. Med J Aust 2016;204(8):320. doi: 10.5694/ mja15.01004

5. National Heart Foundation of Australia. At-risk Australians missing out on CVD assessment. 25 October 2019. Melbourne, Vic: National Heart Foundation of Australia, 2019. Available at https:// resources.heartfoundation.org.au/news/at-riskaustralians-missing-out-on-cvd-assessment [Accessed 27 May 2020].

6. Jansen J, Bonner C, McKinn S, et al. General practitioners' use of absolute risk versus individual risk factors in cardiovascular disease prevention: An experimental study. BMJ Open 2014;4(5):e004812. doi: 10.1136/bmjopen-2014004812.

7. Jackson R, Barham P, Bills J, et al. Management of raised blood pressure in New Zealand: A discussion document. BMJ 1993;307(6896):107-10. doi: 10.1136/ bmj.307.6896.107.

8. Anderson KM, Odell PM, Wilson PW, Kannel WB. Cardiovascular disease risk profiles. Am Heart J 1991;121(1 Pt 2):293-98. doi: 10.1016/00028703(91)90861-b.

9. Damen JAAG, Hooft L, Schuit E, et al. Prediction models for cardiovascular disease risk in the general population: Systematic review. BMJ 2016;353:i2416. doi: 10.1136/bmj.i2416.

10. Albarqouni L, Doust JA, Magliano D, Barr EL, Shaw JE, Glasziou PP. External validation and comparison of four cardiovascular risk prediction models with data from the Australian diabetes, obesity and lifestyle study. Med J Aust 2019;210(4):161-67. doi: 10.5694/mja2.12061.

11. Goff DC Jr, Lloyd-Jones DM, Bennett G, et al. 2013 ACC/AHA guideline on the assessment of cardiovascular risk: A report of the American College of Cardiology/American Heart Association task force on practice guidelines. J Am Coll Cardiol 2014;63(25 Pt B):2935-59. doi: 10.1016/j. jacc.2013.11.005.

12. Scott IA. Evaluating cardiovascular risk assessment for asymptomatic people. BM 2009;338:a2844. doi: 10.1136/bmj.a2844.

13. Hippisley-Cox J, Coupland C, Brindle P. Development and validation of QRISK3 risk prediction algorithms to estimate future risk of cardiovascular disease: Prospective cohort study. BMJ 2017;357:j2099. doi: 10.1136/bmj.j2099.

14. Pylypchuk R, Wells S, Kerr A, et al. Cardiovascular disease risk prediction equations in 400000 primary care patients in New Zealand: A derivation and validation study. Lancet 2018;391(10133):1897-907. doi: 10.1016/S01406736(18)30664-0.

15. Empana JP, Tafflet M, Escolano S, et al. Predicting CHD risk in France: a pooled analysis of the D.E.S.I.R., Three City, PRIME, and SU.VI. MAX studies. Eur J Cardiovasc Prev Rehabil 2011;18(2):175-85. doi: 10.1177/1741826710389354.

16. Lin JS, Evans CV, Johnson E, Redmond N, Coppola EL, Smith N. Nontraditional risk factors in cardiovascular disease risk assessment: Updated evidence report and systematic review for the US preventive services task force. JAMA 2018;320(3):281-97. doi: 10.1001/jama.2018.4242.

17. Curry SJ, Krist AH, Owens DK, et al. Screening for cardiovascular disease risk with electrocardiography: US preventive services task force recommendation statement. JAMA 2018;319(22):2308-14. doi: 10.1001/ jama.2018.6848.

18. Rozanski A, Gransar H, Shaw LJ, et al. Impact of coronary artery calcium scanning on coronary risk factors and downstream testing the EISNER (Early Identification of Subclinical Atherosclerosis by Noninvasive Imaging Research) prospective randomized trial. J Am Coll Cardio 2011;57(15):1622-32. doi: 10.1016/j.jacc.2011.01.019

19. Inouye M, Abraham G, Nelson CP, et al. Genomic risk prediction of coronary artery disease in 480,000 adults: Implications for primary prevention. J Am Coll Cardiol 2018;72(16):1883-93. doi: 10.1016/j.jacc.2018.07.079.

20. Hua X, McDermott R, Lung T, et al. Validation and recalibration of the Framingham cardiovascular disease risk models in an Australian Indigenous 
cohort. Eur J Prev Cardiol 2017:24(15):1660-69. doi: $10.1177 / 2047487317722913$

21. Agostino JW, Wong D, Paige $E$, et al. Cardiovascular disease risk assessment for Aboriginal and Torres Strait Islander adults aged under 35 years: A consensus statement. Med J Aust 2020:212(9):422-27. doi: 10.5694/ mja2.50529.

22. Tinetti $M E$, Naik $A D$, Dindo $L$, et al. Association of patient priorities-aligned decision-making with patient outcomes and ambulatory health care burden among older adults with multiple chronic conditions: A nonrandomized clinical trial. JAMA Intern Med 2019;179(12):1688-97. doi: 10.1001/ jamainternmed.2019.4235.

23. Montori VM, Brito JP, Ting $\mathrm{HH}$. Patient-centered and practical application of new high cholesterol guidelines to prevent cardiovascular disease. JAMA 2014;311(5):465-66. doi: 10.1001/ jama.2014.110.

24. Sheridan SL, Viera AJ, Krantz MJ, et al. The effect of giving global coronary risk information to adults: A systematic review. Arch Intern Med 2010;170(3):230-39. doi: 10.1001/ archinternmed.2009.516.

25. Albarqouni L, Doust J, Glasziou P. Patient preferences for cardiovascular preventive medication: A systematic review. Heart 2017;103(20):1578-86. doi: 10.1136/ heartjnl-2017-311244.

26. Bonner C, Jansen J, McKinn S, et al. General practitioners' use of different cardiovascular risk assessment strategies: A qualitative study. Med J Aust 2013;199(7):485-89. doi: 10.5694/ mja13.10133.

27. Bonner C, Fajardo MA, Hui S, Stubbs R, Trevena L. Clinical validity, understandability, and actionability of online cardiovascular disease risk calculators: Systematic review. J Med Internet Res 2018;20(2):e29. doi: 10.2196/jmir.8538.

28. Bonner C, Patel P, Fajardo MA, Zhuang R, Trevena L. Online decision aids for primary cardiovascular disease prevention: Systematic search, evaluation of quality, and suitability for low health literacy patients. BMJ Open 2019;9:e025173. doi: 10.1136/bmjopen-2018025173.

29. Trevena LJ, Zikmund-Fisher BJ, Edwards A, et al. Presenting quantitative information about decision outcomes: A risk communication primer for patient decision aid developers. BMC Med Inform Decis Mak 2013;13(Suppl 2):S7. doi: 10.1186/1472-6947-13-S2-S7.

30. Bonner C, McKinn S, Lau A, et al. Heuristics and biases in cardiovascular disease prevention: How can we improve communication about risk, benefits and harms? Patient Educ Couns 2018;101(5):843-53. doi: 10.1016/j.pec.2017.12.003

31. Bonner C, Bell K, Jansen J, et al. Should heart age calculators be used alongside absolute cardiovascular disease risk assessment? BMC Cardiovasc Disord 2018;18(1):19. doi: 10.1186/ s12872-018-0760-1.

32. Kulendrarajah B, Grey A, Nunan D. How effective are 'age' tools at changing patient behaviour? A rapid review. BMJ Evid Based Med 2020;25(2):1-2 doi: 10.1136/bmjebm-2019-111244.

33. Wells $S$, Kerr A, Eadie S, Wiltshire C, Jackson R. 'Your Heart Forecast': A new approach for describing and communicating cardiovascular risk? Heart 2010;96(9):708-13. doi: 10.1136/ hrt.2009.191320.

34. Ministry of Health. Cardiovascular disease risk assessment and management for primary care. Wellington, New Zealand: Ministry of Health, 2018.
35. Gabb GM, Mangoni AA, Anderson CS, et al. Guideline for the diagnosis and management of hypertension in adults - 2016. Med J Aust 2016;205(2):85-89. doi: 10.5694/mja16.00526.

36. Whelton PK, Carey RM, Aronow WS, et al. 2017 ACC/AHA/AAPA/ABC/ACPM/AGS/APhA/ASH/ ASPC/NMA/PCNA guideline for the prevention, detection, evaluation, and management of high blood pressure in adults: A report of the American College of Cardiology/American Heart Association task force on clinical practice guidelines. J Am Coll Cardiol 2018;71(19):e127-e248. doi: 10.1016/j. jacc.2017.11.006.

37. National Institute for Health and Care Excellence. Hypertension in adults: Diagnosis and management. London, UK: NICE, 2019.

38. Pencina MJ, Navar-Boggan AM, D'Agostino RB Sr, et al. Application of new cholesterol guidelines to a population-based sample. N Engl J Med 2014:370(15):1422-31. doi: 10.1056/ NEJMoa1315665. 